\title{
Investigation of the Violence and Violence Types against the Healthcare Staff Working in 112 Emergency Service
}

\author{
Leyla Yaka ${ }^{1}$ and Nalan Gördeles Beşer ${ }^{2 *}$ \\ ${ }^{1}$ Emergency Medical Technician, Niğde 112 Emergency Service, Turkey \\ ${ }^{2}$ Department of Nursing/Department of Psychiatric Nursing, Niğde Zübeyde Hanım Vocational \\ Health School, Niğde Ömer Halisdemir University, Turkey
}

*Corresponding author: Nalan Gördeles Beşer, Asst. Prof., Department of Nursing/Department of Psychiatric Nursing, Niğde Zübeyde Hanım Vocational Health School, Niğde Ömer Halisdemir University, Derbent Campus Niğde/Merkez 51200, Turkey, Tel: 03882112817, Fax: 03882112813

\begin{abstract}
Objective: This study was carried out to investigate the violence and violence types committed against healthcare staff working in the 112 emergency service.

Materials and methods: This study was conducted between the dates of December 2015 and June 2016 with 100 healthcare staff (physicians and other personnel) working in emergency service stations, in the chief physician department of 112 , and in the command and control center of 112 , all of which fall within the body of the Niğde Provincial Directorate of Health. Before conducting the study, written permission to perform the study was obtained from the Niğde Ömer Halisdemir University's Ethical Committee and the Niğde Provincial Directorate of Health. The data were collected using the "Violent Incident Form", developed by Arnetz (1998). The SPSS package was used to evaluate the data, and the numbers were evaluated using percentage.
\end{abstract}

Findings: The study found that $83 \%$ of the healthcare staff had been subject to violence. Most of the healthcare staff who had been subject to violence had experienced violence more than once, and the type of violence committed by male assailants (patients and relatives of patients) was largely verbal violence or aggression.

Conclusion: Violence in health facilities has become a universal problem, and prevention efforts have been pursued, not only in Turkey, but throughout the world.

\section{Keywords}

Violence, Violence types, 112 Emergency service, Patient, Patient relatives

\section{Introduction}

Violence is a major health problem, one that is responsible for causing trauma and permanent damage to people's lives. There are many types of violence and many incidences of violence in every part of life. Violence has been known to take place in the work places of many sectors, especially in health facilities and hospitals $[1,2]$. This poses a major problem for physicians, nurses, and other health staff working in health facilities and also for the patients and patient' relatives receiving services from these organizations. In one study, 544 of the healthcare staff $(50.8 \%)$ reported that they had been subject to violence in their work places [3], while in a study conducted in Australia, it was reported that $72 \%$ of the health professionals and $62 \%$ of the nurses and practitioners had been subject to violence in their working environment [4]. Considering that healthcare staff are under greater risk of being subject to violence than that of workers in other sectors, the studies related to this subject have focused on the state of patients or patient' relatives committing the violence and the reasons responsible for generating these incidences of violence. The health facilities provide services to patient' relatives who have taken on the responsibility of helping their family members or other patients to deal with the symptoms of their illness. It could be argued that the violence committed by patients and their relatives results from the stress they are under, the anxiety

Citation: Yaka L, Beşer NG (2018) Investigation of the Violence and Violence Types against the Healthcare Staff Working in 112 Emergency Service. Int Arch Nurs Health Care 4:100. doi.org/10.23937/24695823/15100100

Accepted: September 27, 2018: Published: September 29, 2018

Copyright: (C) 2018 Yaka L, et al. This is an open-access article distributed under the terms of the Creative Commons Attribution License, which permits unrestricted use, distribution, and reproduction in any medium, provided the original author and source are credited. 
they experience from uncertainty, their lack of knowledge about the treatment period of the illness, the bureaucracy in health facilities, the roles and responsibilities of health professionals, and the inability of the patients or their relatives to express themselves, which leads to their demand for emergency help through the recourse of violence. Patients and their relatives are more liable to attack health professionals in emergency clinics that provide 24-hour service and where the first intervention is applied, as it is during this time that emotions tend to run high. Because emergency clinics is the first clinic that patients apply for more need and afraid. So patients and their relatives are not able to understand health professional intervention. So they attach easily to health professional. Consequently, the pressure of trying to carry out the best intervention for the patient, which is vitally important, coupled with the violence committed by patient' relatives can leave the healthcare staff in a difficult situation [5-7]. Therefore, it is very important to identify the factors leading people to against violence on healthcare staff and to take the necessary precautions $[3,8,9]$. This study aims to identify the violence and violence types committed on health professionals working at 112 emergency service stations in Niğde province. The results of this study will be shared with the relevant authorities, and a database including these results will be built for the purpose of assisting physicians, nurses, emergency medical technicians with associate degrees, and other healthcare staff working in 112 emergency services in facing the problems of violence in their workspace.

\section{Method}

\section{Design}

This is a cross-sectional study, conducted to determine the violence and violence types to which 112 emergency service healthcare staff are subject. The sample included 100 healthcare staff who were working in 112 chief physician department. All participants agreed to take part in the study and were performing their duties on the date the study was conducted.

\section{Measurement}

The data were collected using the Violent Incident Form (violence questionnaire applied to healthcare staff) developed by Arnetz (1998). This form, which was adapted for use in Turkey, consists of 16 questions related to the frequency in which staff members are subject to violence, the site of the act of violence, whether the personnel was alone or not, the reaction against the act of violence, and the result [3].

\section{Ethical considerations}

Prior to conducting the study, the researcher received written permission of Niğde Provincial Directorate of Health (approval no. 09, dated 21.12.2015) and the Ethical Committee of Niğde Ömer Halisdemir Uni- versity. Informed verbal consent to participate in the study was obtained from all participants after they were informed of the study objective.

\section{Statistical analysis}

Data analyses were conducted using SPSS, and the numbers were evaluated by converting them to percentage.

\section{Results}

Among the participants of the study, $56 \%$ were female, $44 \%$ were male, $72 \%$ were married, $38 \%$ were high school graduates, and $4 \%$ held master's degrees. Regarding all the health professionals, $83 \%$ had been subject to violence (physicians (4\%), emergency medical technicians with associate degrees (19\%), emergency medical technicians with high school degrees (49\%), drivers $(22 \%)$, other working staff $(6 \%)), 45 \%$ were 30 years or younger, $44 \%$ were between the ages of 31-40, and $50 \%$ had been working for five years or less, $39 \%$ for $6-10$ years, and $11 \%$ for 11 years or more (Table 1 ).

Considering the participants who had been subject to violence, $49.4 \%$ had experienced it more than five times and $16.9 \%$ had been subject to violence only once; $81.9 \%$ had experienced violence in the form of verbal threats and/or aggression and $7.2 \%$ in the form of kicking and/or pushing; and $72.3 \%$ had been subject to violence from the relatives of patients, $24.1 \%$ from the patients, and $2.4 \%$ from personnel (Table 1 ).

It was found, per the reports taken from healthcare staff, that they had been violence at a rate of $90.4 \%$ in emergency service, $7.2 \%$ in the examination room, and $1.2 \%$ in the waiting room; in $94 \%$ of cases the staff member was not alone when these acts of violence occurred. Regarding the reactions against violence, $37.3 \%$ of the staff did not respond, $34.9 \%$ responded out of self-defense, and $14.5 \%$ appealed for help. Regarding the question of why the assailant had attacked, $45.8 \%$ did not know the reason, $27.7 \%$ felt that the assailant might have had mental problems, and $26.5 \%$ stated that the assailant could have been under the influence of alcohol or drugs (Table 1).

Finally, prior to the act of violence, $32.5 \%$ of the healthcare staff stated they had been speaking with the assailant, $31.3 \%$ had been assisting the assailant to transfer/raise/help the patient physically, $20.5 \%$ had been administering treatment/therapy/physical care, and $8.4 \%$ stated that they had been engaged in other actions. In terms of the result of the violent incident, $84.3 \%$ of the staff declared that no judicial or administrative action was taken, while $15.7 \%$ indicated that the police took a report of the incident (Table 1).

\section{Discussion}

In this study, among the healthcare staff, $56 \%$ of the participants were female, $72 \%$ were married, $38 \%$ were 
Table 1: Violence and violence types committed against healthcare staff.

\begin{tabular}{|c|c|c|}
\hline Statements & Number & Percen \\
\hline \multicolumn{3}{|l|}{ Subject to violence status $(n=100)$} \\
\hline Have been subject to violence & 83 & 83 \\
\hline Have not been subject to violence & 17 & 17 \\
\hline \multicolumn{3}{|c|}{ How frequently have you been subject to violence? $(n=83)$} \\
\hline Once & 14 & 16.9 \\
\hline Two times & 13 & 15.7 \\
\hline Three times & 13 & 15.7 \\
\hline Four times & 2 & 2.4 \\
\hline Five or more times & 41 & 49.4 \\
\hline \multicolumn{3}{|l|}{ Type of violence committed $(n=83)$} \\
\hline Verbal threats or aggression & 68 & 81.9 \\
\hline Kick & 6 & 7.2 \\
\hline Slap & 1 & 1.2 \\
\hline Battery & 1 & 1.2 \\
\hline Push & 6 & 7.2 \\
\hline Use of a gun & 1 & 1.2 \\
\hline \multicolumn{3}{|c|}{ Who have you been attacked by? $(n=83)$} \\
\hline Patient & 20 & 24.1 \\
\hline Patient relatives & 60 & 72.3 \\
\hline Personnel & 2 & 2.4 \\
\hline Other & 1 & 1.2 \\
\hline \multicolumn{3}{|l|}{ Gender of assailant $(n=83)$} \\
\hline Male & 73 & 88 \\
\hline Female & 10 & 12 \\
\hline
\end{tabular}

Were you working alone when the act of violence occurred? $(n=83)$

\begin{tabular}{|l|l|l|}
\hline Yes & 5 & 6 \\
\hline No & 78 & 94 \\
\hline
\end{tabular}

The place where you were attacked $(n=83)$

\begin{tabular}{|l|l|l|}
\hline Waiting room & 1 & 1.2 \\
\hline Emergency service & 6 & 7.2 \\
\hline Examination room & 1 & 1.2 \\
\hline Other - act on-site & \multicolumn{1}{|l|}{75} & 90.4 \\
\hline What was your reaction against the violence? & (n = 83) \\
\hline I defended myself & 29 & 34.9 \\
\hline I asked for help & 12 & 14.5 \\
\hline Others came to help & 11 & 13.3 \\
\hline No action was necessary & 31 & 37.3 \\
\hline
\end{tabular}

What do you think is the reason the assailant attacked you? ( $\mathrm{n}=\mathbf{8 3}$ )

\begin{tabular}{|l|l|l|}
\hline Mental problem & 23 & 27.7 \\
\hline Influence of alcohol or drugs & 22 & 26.5 \\
\hline I do not know & 38 & 45.8 \\
\hline
\end{tabular}

What were you doing just before the act of violence? $(n=83)$

\begin{tabular}{|l|l|l|}
\hline Treatment/therapy/physical care & 17 & 20.5 \\
\hline Speaking & 27 & 32.5 \\
\hline $\begin{array}{l}\text { Transferring/raising/helping the patient } \\
\text { physically }\end{array}$ & 26 & 31.3 \\
\hline No action & 4 & 4.8 \\
\hline Requests by the patient & 2 & 2.4 \\
\hline Other & 7 & 8.4 \\
\hline
\end{tabular}

How was the violent act concluded? $(n=83)$

\begin{tabular}{|l|l|l|}
\hline The police wrote up a report & 13 & 15.7 \\
\hline $\begin{array}{l}\text { No judicial or administrative action was } \\
\text { taken }\end{array}$ & 70 & 84.3 \\
\hline
\end{tabular}
taken

high school graduates, and $83 \%$ had been subject to violence (4\% physicians, $19 \%$ emergency medical technicians with associate degrees, $49 \%$ emergency medical technicians with high school degrees, 22\% drivers, and $6 \%$ other personnel). Ayrancl, et al. [3], in their study, found the violence rate related to the healthcare staff to be less $(50.8 \%)$ than that of the present study [3], whereas in another study, the rate of $87 \%$ was reported, which is similar to the one reported in the present study [7]. Considering the frequency of being subject to violence, it was found that among the healthcare staff, $49.4 \%$ had faced violence more than five times, $16.9 \%$ had faced it once, $15.7 \%$ three times, and $2.4 \%$ four times. The study conducted by Akça, et al. [5] reported that among the healthcare staff who had been subject to violence, $28.6 \%$ experienced it more than five times, $33.3 \%$ once, $19 \%$ two times, and $14.3 \%$ three times [5]; in contrast, in the study conducted by Ayrancl, et al., it was indicated that $48.3 \%$ of the healthcare staff had experienced violence at least once and at most five times [3]. Although the rates and frequencies related to the healthcare staff's subjection to violence differ, the fact that the rates reported in three studies were greater than fifty percent and that a significant percent of staff had been subjected to violence on more than one occasion clearly demonstrates that healthcare staff are exposed to violence $[1,10-12]$.

The results from this study showed that $81.9 \%$ of the healthcare staff experienced violence in the form of verbal threats and aggression, $7.2 \%$ in the form of kicking and/or pushing, and $1.2 \%$ in the form of slapping and/or battery. In contrast to these results, one study reported that among the staff that had been subject to violence, all had reported to have been exposed to verbal abuse and aggression [5]. Another study, however, indicated that among the healthcare staff who had been subject to violence at any point throughout their professional life, $15.8 \%$ had been subject to physical violence, $98.5 \%$ to verbal abuse, $24 \%$ to bullying/ psychological mobbing, and $6 \%$ to sexual abuse [8]. In another study, it was reported that of the participants, $98.5 \%$ had been subjected to verbal abuse and $19.7 \%$ to physical violence [1]. The healthcare staff in the present study had experienced more verbal abuse than physical abuse likely because the assailants, being under intensive stress due to the nature of the situation they were in, could not express themselves effectively in asking for help, and therefore turned toward violent forms of communication.

The present study found that the violence that the healthcare staff were subjected to was applied by patient relatives in $72.3 \%$ of cases, by the patient in $24.1 \%$ of cases and by the personnel in $2.4 \%$ of cases. Similar to the results from this study, in the study by Çamçı and Kutlu [8], it was reported that the majority of the violence committed against healthcare staff was verbal abuse (89.9\%) and perpetrated by patient relatives [8]. These results suggest that patient relatives, who are struggling to help their family member, are under intense stress and therefore less able to control their anger. 
This study found that $88 \%$ of the assailants were men, while $12 \%$ were women. Similarly, Akça, et al. [5] reported in their study that $76.2 \%$ of the assailants were men [5], with another study supporting these results, stating that the majority of assailants were men [8]. The fact that most of the assailants were men could imply that men are less adept than women in terms of coping with stress, anger management, and verbal communication.

It was stated that among the 112 healthcare staff who had been subject to violence, $90.4 \%$ experienced these incidences in the emergency service $7.2 \%$, in the examination room, and $1.2 \%$ in the waiting room. Akça, et al. [5] reported in their study that violence against healthcare staff had occurred in the examination room in $45.5 \%$ of cases, and in the corridor with $22.7 \%$ [5]. These results draw attention to the fact that violence tends to occur when the healthcare staff first meet their patients, which is the most stressful moment for parties.

The reactions of the participants toward the acts of violence they experienced can be summarized as follows; $37.3 \%$ of the staff did not respond, $34.9 \%$ responded out of self-defense, $14.5 \%$ appealed for help, and $13 \%$ stated that others came to help. Çamçı and Kutlu [8] reported in their study that $78.1 \%$ of the attacked staff responded to the attacks [8]. Akça, et al. [5] indicated in their study that $36.4 \%$ of the attacked personnel did not take any action, while $27.3 \%$ responded to the attack out of self-defense, $22.7 \%$ appealed for help, and $13.6 \%$ came for help from the close vicinity [5].

Results on the reasons why an assailant carries out an attack showed that among the healthcare staff, $45.8 \%$ did not know the reason, $27.7 \%$ felt that the assailant probably suffered from mental problems, $26,5 \%$ would be under the influence of alcohol or drugs. Akça, et al. [5] reported in their study that $54.5 \%$ of the attacked persons thought the assailants might have mental problems, while $45.5 \%$ had no idea [5]. The belief expressed by most of the healthcare staff that assailants might have mental problems could stem from the fact they were interested in trying to understand the patients and their relatives, despite their violent outbursts, and that under normal circumstances, neither the patients nor their relatives would commit violence. Another reason for the predominance of the belief that the assailants had mental problems could be that the healthcare staff felt that the mental health of the patients and their relatives was negatively influenced under intensive stress.

Prior to the attack, in $32.5 \%$ of the cases, the healthcare staff were trying to speak to the patient or their relative, in $31.3 \%$ of the cases, they were helping the relative of the patient to transfer/raise/help the patient physically, in $20.5 \%$ they were administering treatment/ therapy/physical care, and in $8.4 \%$, they were engaged in other actions. The study by Akça, et al. [5] reported that among the staff who had been subjected to violence, $38.1 \%$ had been engaged in examination, treat- ment or physical care prior to the attack, while $28.6 \%$ had been speaking with the assailant [5]. These results suggest that the risk of being exposed to violence increases when staff is physically close to patients.

Lastly, regarding the issue of what resulted from the incident of violence, this study found that $84.3 \%$ of the staff declared that no judicial or administrative action was taken, while $15.7 \%$ indicated that the police wrote a report on the incident. Akça, et al. [5] reported in their study that no judicial or administrative action was taken regarding victims [5]. These findings show that no protection is provided to healthcare staff, that the violence is deemed to be normal, and that the staff ignore it, choosing instead to concentrate on helping the patients and their relatives.

\section{Conclusion}

The great majority of healthcare staff who are attacked encounter more than one violence type. This study indicated that the violence by male assailants who were either patients or relatives of the patient was committed mostly in the form of verbal threats or aggression. Most of the attacked 112 healthcare staff stated that they did not respond in any way to the violence, but there were some who reported that they defended themselves and responded to the assailants. Moreover, it was found that the acts of violence mostly occurred on-site, during patient transfer, at the moment a staff member was trying to administer the patient treatment/therapy/physical care or when the staff member was trying to speak with the patient, and that generally no judicial or administrative action was taken after the act of violence. These findings bring attention to the presence of violence committed against healthcare staff and the risks involved in dealing with patients and their relatives in terms of the violence they are capable of displaying under intense stress. The participating staff further demonstrated that while it is more reasonable to seek to understand and help patients and relative of patients when they are under stress and showing signs of violence, the staff nonetheless cannot always protect themselves against violence. Therefore, bureaucratic measures should be established in emergency clinics to protect healthcare staff against violence. Moreover, the number of staff should be increased, and to reduce incidences of violence during medical interventions, patients and their relatives should be provided with emotional support. Furthermore, physical regulations should be instituted in emergency clinics to prevent violence. Healthcare staff, whose job it is to help people, have the right to safe working conditions. It is important that the Ministry of Health, health facilities, healthcare staff, patients, patient relatives and the media cooperate and take the necessary precautions to solve the violence issue in health facilities.

\section{Acknowledgment}

We would like to thank the Provincial Directorate of Health and all the healthcare staff who participated in the study for making this study possible. 


\section{Conflict of Interest}

The researchers declare that there is no conflict of interest.

\section{References}

1. Annagür B (2010) Violence towards health care staff: Risk factors, aftereffects, evaluation and prevention. Psikiyatride Güncel Yaklaşımlar 2: 161173.

2. Eker HH, Topcu İ, Şahinöz S, Özder A, Aydın H (2011) The frequency of violence in a training in one of the research hospital. Bidder Tıp Bilimleri Dergisi 3: 16-22.

3. Ayrancı Ü, Yenilmez Ç, Günay Y, Kaptanoğlu C (2002) The incidence of violence in various health institutions and health professions. Anadolu Psikiyatri Dergisi 3: 147-154.

4. Alexander C, Fraser J (2004) Occupational violence in an Australian healthcare setting: Implications for managers. J Healthc Manag 49: 377-390.

5. Akça N, Yılmaz A, Işık O (2014) Violence against Health Workers: A Case of a Special Medical Center. Ankara Sağlık Hizmetleri Dergisi 13.
6. Aktuğlu K, Hanci H (1999) The threat of violence in the emergency room. Legal Responsibility and Rights of Physician. Ege Üniversitesi Tıp Fakültesi, Toprak Ofset, İzmir, 1-7.

7. Behçet Al, Suat Zengin, Yahya Deryal, Cem Gökçen, Demet Arı Yılmaz, et al. (2012) Increased violence towards health care staff. JAEM 11: 115-124.

8. Çamcı O, Yasemin K (2011) Determination of Workplace Violence Toward Health Workers in Kocaeli. J Psy Nurs 2: 9-16.

9. Elliott PP (1997) Violence in health care. What nurse managers need to know. Nurs Manage 28: 38-41.

10. Ergün FS, Karadakovan A (2005) Violence towards nursing staff in emergency departments in one Turkish city. Int Nurs Rev 52: 154-160.

11. Gülalp B, Karcıoğlu O, Köseoğlu Z, Sarı A (2009) Dangers faced by emergency staff: Experience in urban centers in southern Turkey. Ulus Travma Acil Cerrahi Derg 15: 239-242.

12. Pemberton MN, Atherton GJ, Thornhill MH (2000) Violence and aggression at work. Br Dent J 189: 409-410. 